\title{
QUARTERLY MONITORING OF SUSPECTED ILLEGAL HUMAN ACTIVITIES IN NATIONAL NATURE RESERVES OF CHINA WITH SENTINEL-2 AND HIGH- RESOLUTION IMAGES ON THE CLOUD PLATFORM
}

\author{
Hao Wang ${ }^{1}$, Xiaogang Ning ${ }^{1, *}$, Quan Dong ${ }^{2}$, Yafei Liu ${ }^{1}$, Minghui Hao ${ }^{1}$, Hanchao Zhang ${ }^{1}$, Han Wang ${ }^{1}$, Wentao Chang ${ }^{1,3}$, \\ Yinxuan Cao ${ }^{1}$, Caijuan Liu ${ }^{1}$ \\ Institute of photogrammetry and remote sensing, Chinese Academy of Surveying and Mapping, Beijing, China - (wanghao, \\ ningxg)@casm.ac.cn \\ ${ }^{2}$ National Quality Inspection and Testing Center for Surveying and Mapping Products, Beijing, China \\ ${ }^{3}$ College of Geomatics, Shandong University of Science and Technology, Qingdao, China
}

Commission III, WG III/7

KEY WORDS: Land cover change, High-precision historical images, Siweiearth, Google earth, Google earth engine, National Geoinformation Survey Data of China, Multi-source data

\begin{abstract}
:
Nature reserves play an important role in protecting biodiversity, preserving natural heritage, and maintaining national ecological security. Satellite remote sensing technology has become an essential way to capture the impact of human activities on nature reserves by monitoring the land cover change. However, current monitoring frequency and scale were inadequate to detect the land change related to illegal human activities rapidly and accurately. To solve the above problems, this study proposed an operational suspected illegal change detection method which combined the temporal advantage of Sentinel-2 double satellites with the spatial advantage of high-resolution images from SiweiEarth and Google Earth cloud platforms, together with high-precision highresolution images from cloud platforms, historical land cover data from Geoinformation Survey Data of China, and the thematic information of study area. Eight typical national nature reserves were selected as study areas. January 1st, 2019 was taken as the time point of the base period. May 31st, August 31st, and November 30th were taken as the time point of the first period, the second period, and the third period respectively. Results showed that four national nature reserves had nine suspected illegal land change parcels, with a good ecological protection situation of the other four nature reserves. Deforestation and illegal construction were the two main suspected illegal types. In the next step, the study results will be provided to the Law Enforcement Administration of China to evaluate the applicability and generalization of this method, and a more rapid and intelligent method needs to be improved.
\end{abstract}

\section{INTRODUCTION}

Nature reserves play an important role in maintaining national ecological security, protecting biodiversity, preserving natural heritage, and improving the quality of the ecological environment (Laurance et al., 2014; Le Saout et al., 2013). However, the current nature reserves are facing threat by both natural and human activities(Qian et al., 2019). Human activity is a significant factor affecting nature reserves besides climate change, including deforestation, mineral resources and energy development, quarrying and sand mining, agricultural reclamation, water conservancy construction, tourism development and urbanization (Keenan et al., 2015; MacDicken, 2015; Mayra Cristina Prado et al., 2017). Nature reserves widely distribute in large areas, so it is difficult to achieve full coverage and comprehensive supervision by traditional ground surveys, making it impossible to discover ecological damage and violations in time.

Land cover change is a significant reflection of human activities (López-Angarita et al., 2018; Rodríguez-Rodríguez et al., 2015). Land cover changes caused by human activities have changed the habitats and types of wildlife, and have an essential impact on biodiversity (Edwin et al., 2019). Satellite remote sensing technology has become an indispensable way to capture the impact of human activities on nature reserves. A large number of studies have been carried out to analyze the influence of human activities on nature reserves from the perspective of land cover change. Agricultural activities encroach on natural land cover of nature reserves, and woodlands and shrublands have decreased significantly, posing a threat to wildlife corridors and scattered areas (Edwin et al., 2019). The conversion of forest to farmland and the urban expansion, at the cost of farmland loss, has a profound impact on climate, biodiversity, and human health (Feddema et al., 2005). The wetland area of Lake Aibi Wetland National Nature Reserve in China had decreased by 22\% from 1972 to 2013, which had an important impact on ecological security (Yu et al., 2017).

However, studies were concentrated on the annual land cover change monitoring with high-resolution images or land cover change monitoring with low and medium-resolution images (Liu et al., 2018; Ministry of Natural Resources, 2019). Few studies combined the temporal resolution with spatial resolution. At the same time, the monitoring frequency and scale, which had been carried out, were inadequate to meet the business needs of rapid and accurate detection of illegal human activities. This research aims at developing a business-based suspected illegal change detection method that combines the advantages of medium-resolution and high-resolution, together with the historical land cover data and thematic information.

* Corresponding author 


\section{MATERIALS AND METHODS}

\subsection{Study Area}

As of April 2018, there are 451 national nature reserves in China. Eight typical national nature reserves, namely Qilian Mountains of Gansu, East Dongting Lake of Hunan, Huichun Siberian Tiger of Jilin, Haba Lake of Ningxia, and Yangtze Alligator of Anhui, Xishuangbanna of Yunnan, Danjiang Wetland of Henan, and Xelinco Black-necked Crane of Tibet, were selected as study areas. Human activities intensity and intensity change were the principal factors for selecting study areas. Regional characteristics, topographic conditions, and types of nature reserves were also taken into account. Human activity intensity indicators were represented by the area and proportion of land cover types related to human activities, such as buildings, structures, railways and roads, and construction sites from 2015 to 2017 .

\subsection{Data and Processing}

The management boundaries of the eight typical national nature reserves came from the Information Center of the Ministry of Natural Resources of China. The boundaries of national nature reserves that include functional areas came from the National Forestry and Grassland Bureau of China. Given the inconsistency between the two sets of boundary data, they were superimposed to get the union regions (maximum range), and the areas beyond the functional areas after the superposition was regarded as the experimental zone. Besides, the functional areas of the East Dongting Lake Nature Reserve were not included in the above boundaries, and they were digitally vectorized based on the East Dongting Lake Functional Areas document issued by the Ministry of Ecology and Environment of China.

Sentinel-2 satellites were launched by ESA, and the double-star collaboration achieves a return period of 5 days, providing an opportunity to discover land cover changes related to human activities quickly. Sentinel-2 multispectral images were processed and downloaded by the Google Earth Engine (GEE) cloud platform. GEE's cloud mask algorithm was used to reconstruct the composite image with the median composition method. Images below $20 \%$ cloud amount were selected for cloudless image synthesis. GEE embedded algorithm ensures the geometric registration accuracy among image data of different data and scene. SiweiEarth cloud platform (https://siweiearth.com/) integrates most of the Gaofen series satellites and Ziyuan-3 satellites of China that are better than 2 meters from January 2018 to the present with a very high timefrequency. Compared with SiweiEarth, Google Earth has a longer image archiving time, but its update frequency is slower in China. Combining SiweiEarth and Google Earth provides high time-frequency images of long archiving time.

Land cover data were gathered from the National Geoinformation Survey Data of the Ministry of Natural Resources of the People's Republic of China and updated annually. The resolution of the images used for land cover data is better than 2 meters, and the quality is guaranteed by manual interpretation and field verification (Ministry of Natural Resources, 2019). It adopts a three-level classification system. There are 10 first-level categories, 52 second-level categories, and 104 third-level categories. First-level categories include cultivated land, forest and grass cover, buildings, traffic networks, structures, construction sites, deserts and bare lands, and waters.

\subsection{Method of Suspected Illegal Land Cover Change Detection}

This study proposed an operational suspected illegal change detection method that combined the temporal advantage of Sentinel-2 double satellites with the spatial advantage of highresolution images from SiweiEarth and Google Earth cloud platforms. The specific technical process includes three steps (Figure 1). Firstly, the medium resolution Sentinel-2 twin satellite images, which have a resolution of 10 meters and a return period of 5 days, were downloaded from Google Earth Engine to discover clues of land cover changes quickly. Secondly, based on SiweiEarth and Google Earth cloud platforms, high-resolution images, such as Gaofen series satellites and Ziyuan-3 with a resolution preferable than 2 meters, were obtained to identify the position and shape of the actual land cover changes related to human activities. Finally, according to the management and control rules of national nature reserves of China, the historical multi-period highresolution images from cloud platforms, the high-precision historical land cover data from National Geoinformation Survey Data of China, together with the thematic information of study areas were combined to determine the suspected illegal land cover changes related to human activities. January 1st, 2019 was taken as the time point of the base period of change detection. May 31st, August 31st, and November 30th were chosen as the time point of the first period, the second period, and the third period respectively.

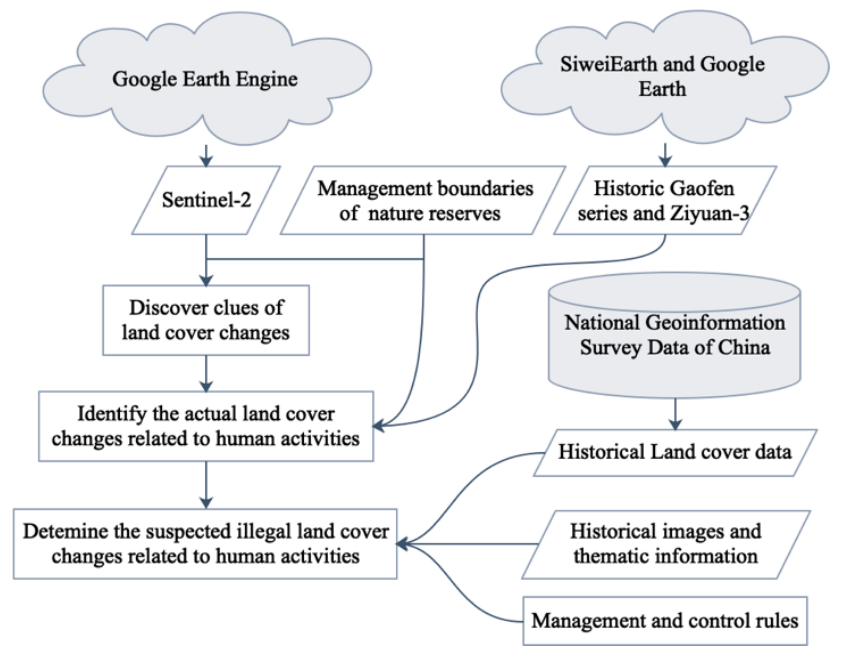

Figure 1. Technical framework of suspected illegal land cover change detection

\section{RESULT AND DISCUSSION}

\subsection{Suspected Illegal Land Cover Change Parcels during the First Monitoring Period}

During the first monitoring period, four suspected illegal land cover change deforestation and construction activities occurred in Xishuangbanna of Yunnan, Yangtze Alligator of Anhui National Nature Reserve.

From December 2018 to April 2019, 8.74 hectares of rubber plantations in the experimental zone of Xishuangbanna National Nature Reserve transformed into bare land (Parcel 01, Figure 2, Table 1). Large-scale deforestation and rubber plantation occurred around Parcel 01 and its surroundings in 2012. In December 2018, Parcel 01 was still a rubber plantation. As of 
Table 1 Suspected illegal land cover changes related to human activities in typical national nature reserves of China in 2019

\begin{tabular}{|c|c|c|c|c|c|}
\hline $\begin{array}{l}\text { Name of National } \\
\text { Nature Reserve }\end{array}$ & $\begin{array}{l}\text { Parcel } \\
\text { number }\end{array}$ & $\begin{array}{l}\text { Monitoring } \\
\text { period }\end{array}$ & $\begin{array}{l}\text { Land cover of } \\
\text { preceding phase }\end{array}$ & $\begin{array}{l}\text { Land cover of } \\
\text { post phase }\end{array}$ & Area (ha) \\
\hline \multirow{2}{*}{$\begin{array}{l}\text { Xishuangbanna of } \\
\text { Yunnan }\end{array}$} & Parcel 01 & First period & Rubber Plantation & Tea plantation & 8.74 \\
\hline & Parcel 02 & First period & Forest & $\begin{array}{l}\text { Bare land and } \\
\text { barren grassland }\end{array}$ & 5.19 \\
\hline \multirow{4}{*}{$\begin{array}{l}\text { Yangtze Alligator of } \\
\text { Anhui }\end{array}$} & Parcel 03 & First period & Forest & Cultivated land & 2.34 \\
\hline & Parcel 04 & First period & Construction Site & Building & 1.56 \\
\hline & Parcel 05 & Second period & Forest & grassland & 3.36 \\
\hline & Parcel 06 & Third period & Forest & Road & 5.26 \\
\hline \multirow{2}{*}{$\begin{array}{l}\text { Haba Lake of } \\
\text { Ningxia }\end{array}$} & Parcel 07 & Third period & Young Plantation & Construction Site & 2.38 \\
\hline & Parcel 08 & Third period & Cultivated land & Building & 0.17 \\
\hline \multirow{2}{*}{$\begin{array}{l}\text { Danjiang Wetland of } \\
\text { Henan }\end{array}$} & \multirow{2}{*}{ Parcel 09} & \multirow{2}{*}{ Third period } & \multirow{2}{*}{ Forest and Shrub } & Road & 4.37 \\
\hline & & & & Construction Site & 0.24 \\
\hline Total & & & & & 33.61 \\
\hline
\end{tabular}

April 2019, the rubber plantation of Parcel 01 was cut down to bare land, and the forest resources were destroyed.

From December 2018 to April 2019, 5.19 hectares of arbor forests in the experimental zone of Xishuangbanna National Nature Reserve transformed into bare land (Parcel 02, Figure 3, Table 1). From 2001 to 2012, the arbor forest was cut down around Parcel 02, and the deforest range had been expanding. In December 2018, Parcel 02 was still arbor forest. As of April 2019, Parcel 02 was cut down to bare land, and the forest resources were destroyed.

From November 2018 to May 2019, 2.34 hectares of arbor forests in the buffer zone of the Yangtze Alligator National Nature Reserve were cut down to cultivated land (Parcel 03, Figure 4, Table 1). Arbor forest was deforested to cultivated land around Parcel 03 in September 2013, and the range of deforestation had been expanding until November 2018. From November 2018 to May 2019, the arbor forest in Parcel 03 was cut down to cultivated land.

From November 2018 to March 2019, 1.38 hectares of construction sites in the core zone of the Yangtze Alligator National Nature Reserve was transformed into a building (Parcel 04, Figure 5, Table 1). The construction project in the areas where Parcel 04 located was stopped by the Central Environmental Protection Supervision of China on October 18, 2018. From November 2018 to March 2019, 1.38 hectares of construction sites were still constructed as buildings with violation of laws and regulations.

\subsection{Suspected Illegal Land Cover Change Parcels during the Second Monitoring Period}

During the second monitoring period, the deforestation area of Parcel 03 and the construction of Parcel 04 expanded. In other national nature reserves, no illegal land cover changes related to human activities occurred.

From June to August 2019, the deforestations range of arbor forests in Parcel 03 of the Yangtze Alligator National Nature Reserve expanded to the surrounding, forming a new 3.36 hectares of arbor deforestation region with the land cover type of grassland (Parcel 05, Figure 4, Table 1). The total deforestation area of Parcel 03 and Parcel was 5.7 hectares. Construction area of suspected illegal Parcel 04 in the core zone of the Yangtze Alligator National Nature Reserve further expanded to 1.56 hectares in July 2019

\subsection{Suspected Illegal Land Cover Change Parcels during the Third Monitoring Period}

During the third monitoring period, the deforestation areas of Parcel 03 and Parcel 05 expanded further. New suspected illegal deforestation and construction activities occurred in Danjiang Wetland National Nature Reserve.

From September to November 2019, the deforestation range of arbor forests in the buffer zone and experimental zone around Parcel 03 and Parcel 05 of the Yangzte Alligator National Nature Reserve expanded further. A new road over 3 kilometers long occupied the original arbor forest, covering an area of 5.26 hectares (Parcel 06, Figure 4, Table 1).

From March to November 2019, 2.38 hectares of young Plantation in the core zone of the Haba Lake National Nature Reserve transformed into construction sites (Parcel 07, Figure 6, Table 1), and 0.17 hectares of cultivated land next to them transformed into buildings (Parcel 08, Figure 6, Table 1). Parcel 07 was young Plantation from February 2018 to March 2019. It was cut down to a construction site in April 2019, and the construction site still existed As of November 2019. Parcel 08 was cultivated land from 2018 to August 2019, and it transformed into a building by October 2019 .

From March to December 2019, 4.61 hectares of contiguous broad-leaved shrubs and coniferous forests in the core zone, buffer zone and experimental zone of the Danjiang Wetland National Nature Reserve transformed into roads and construction sites (Parcel 09, Figure 7, Table 1). Parcel 09 was broad-leaved shrub forest and coniferous forest from April to August 2018. In March 2019, the forest was deforested and constructed as a road. As of December 2019, the length of the road increased to about 4 kilometers, covering an area of 4.37 
hectares. At the same time, there were 0.24 hectares of construction sites beside the road.

Besides, the rubber plantation deforestation areas of parcel 01

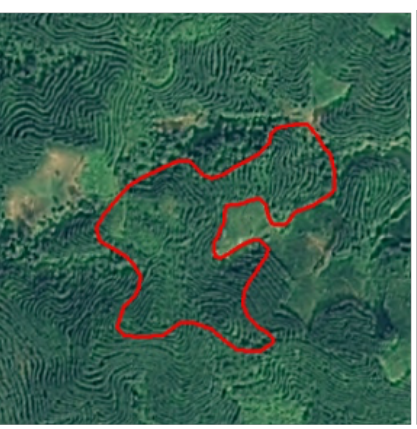

ZY3 image on December 4, 2018

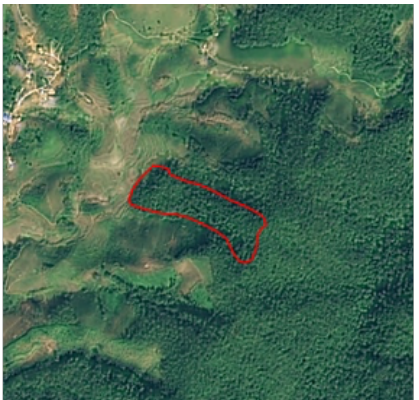

ZY3 image on December 4, 2018

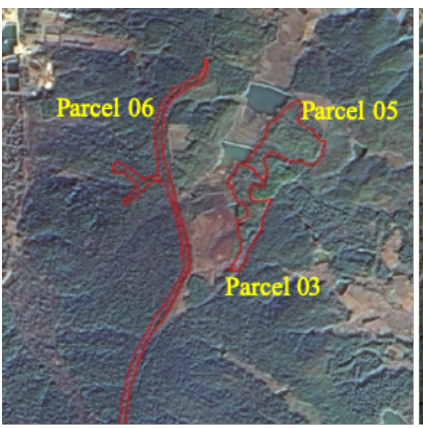

GF1 image on January 22, 2019

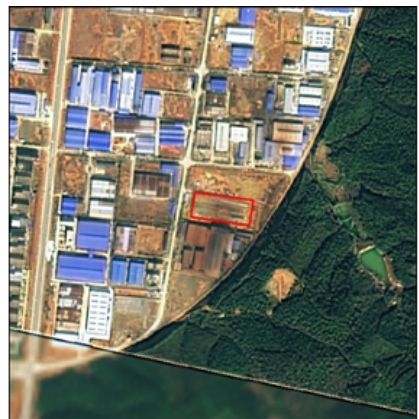

GF1 image on November 28, 2018

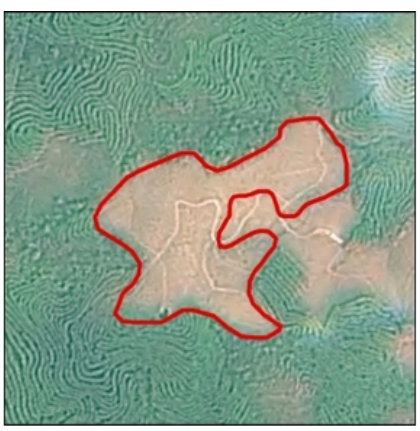

ZY3 image on April 6, 2019

transformed into tea plantation from bare land from May to December 2019 (Figure 2). During the same period, sparse grassland grew in the arbor forest disforestation areas of Parcel 02 (Figure 3).

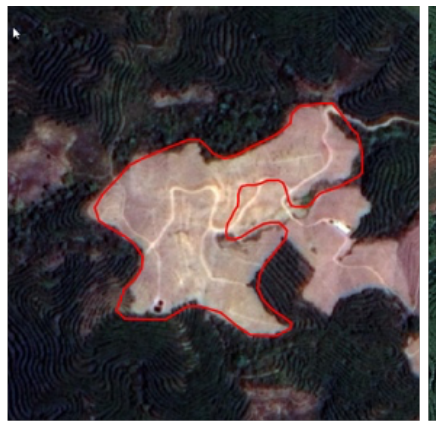

GF1B image on May 8, 2019

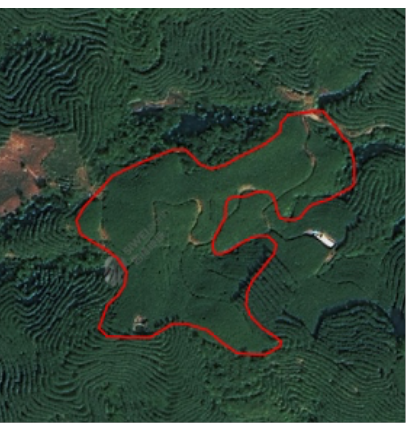

GF1B image on December 10, 2019

Figure 2. Parcel 01 in Xishuangbanna Nature Reserve

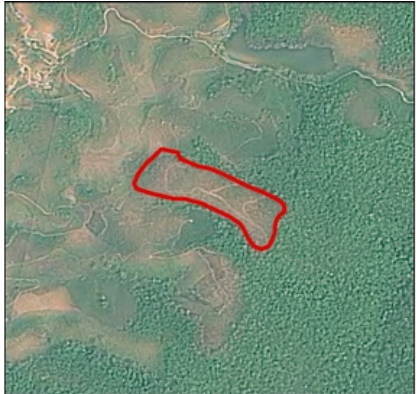

ZY3 image on April 6, 2019

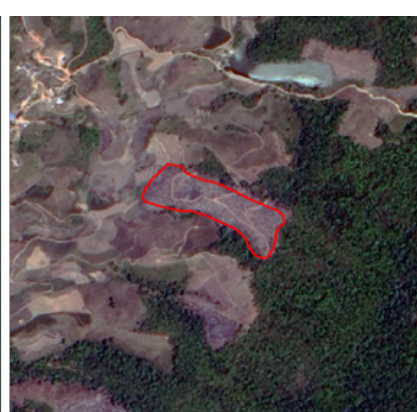

GF1B image on May 8, 2019

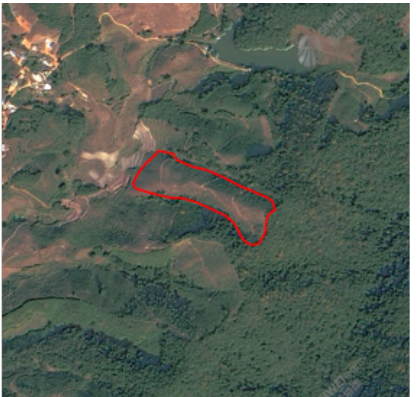

GF1B image on December 15, 2019

Figure 3. Parcel 02 in Xishuangbanna Nature Reserve

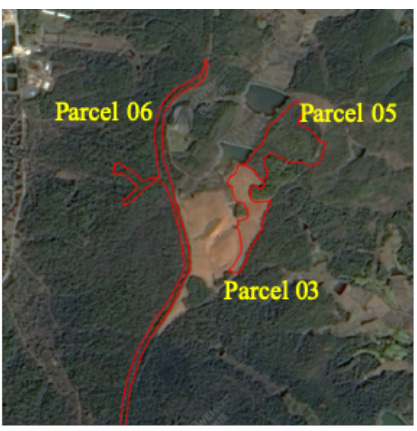

GF1D image on March 26, 2019

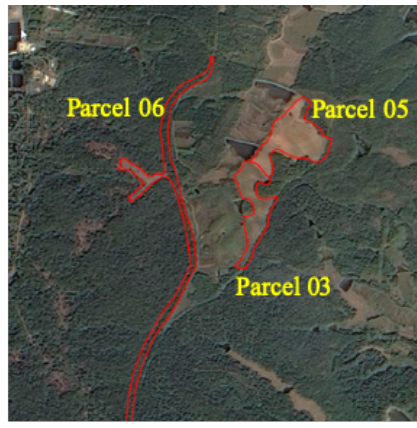

GF1D image on September 30, 2019

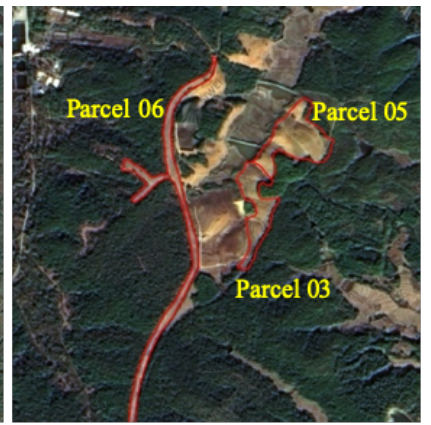

GF6 image on November 22, 2019

Figure 4. Parcel 03, 05 and 06 in Yangtze Alligator Nature Reserve

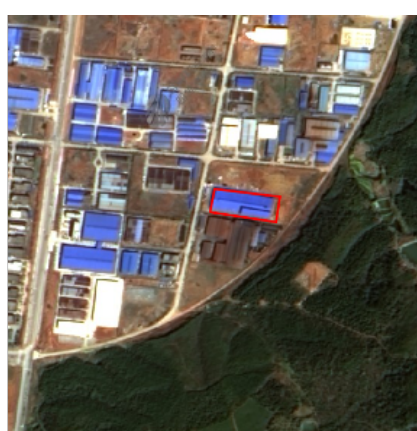

GF1D image on March 26, 2019

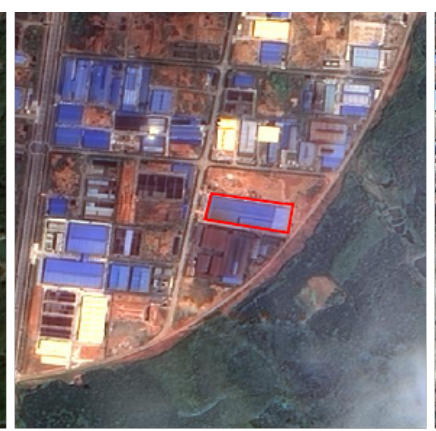

GF1B image on July 28, 2019

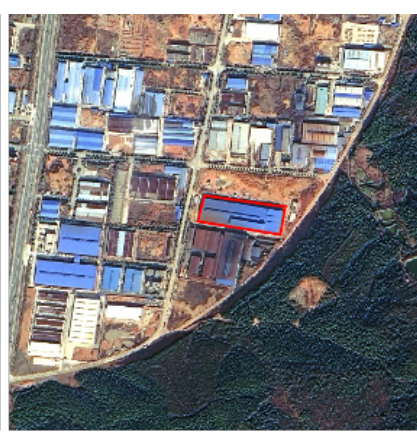

GF2 image on December 16, 2019

Figure 5. Parcel 04 in Yangtze Alligator Nature Reserve 


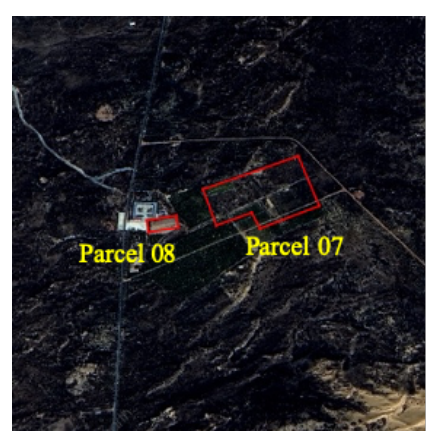

GF2 image on March 18, 2019

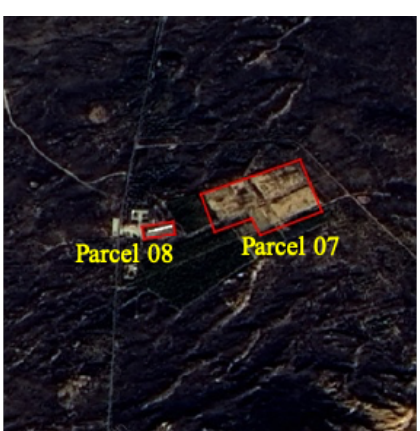

GF1 image on November 22, 2019

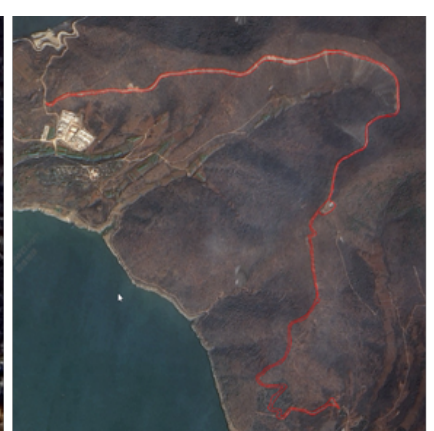

GF2 image on March 7, 2019

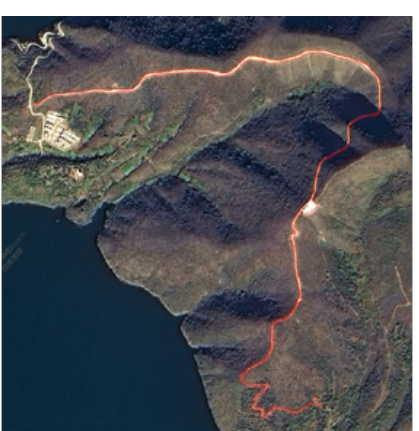

GF1B image on December 3, 2019

Figure 6. Parcel 07 and 08 in Haba Lake Nature Reserve

\section{CONCLUSION}

This paper proposed an operational suspected illegal change detection method which combined the temporal advantage of Sentinel-2 double satellites with the spatial advantage of highresolution images from SiweiEarth and Google Earth cloud platforms, together with historical land cover data from Geoinformation Survey Data of China. The method provided a new perspective for rapid and accurate detection of illegal land cover changes related to human activities.

Among the eight typical national nature reserves, four reserves had nine suspected illegal parcels of land cover change. 8.74 hectares of rubber plantation and 5.19 hectares of arbor forest were deforested in Xishuangbanna National Nature Reserve. 10.96 hectares of arbor forest were cut down for cultivated land, and 1.56 hectares of construction areas were suspected of violation in Yangzte Alligator National Nature Reserve. 2.38 hectares of cultivated land transformed into construction sites from young plantation, and 0.17 hectares of cultivated land transformed into a building in Haba Lake National Nature Reserve. 4.61 hectares of forest were cut down and built as a road in Danjiang Wetland National Nature Reserve.

Next, the suspected illegal parcels of land cover change will be provided to the Law Enforcement Bureau of China to verify the reliability and applicability of the method. In the future, it is suggested that the governments share the shapefile and image data of historical illegal parcels to build a sample database of illegal parcels of land cover change, in order to reduce the field verification and suspected illegal parcels. Also, change detection and knowledge reasoning technology should be improved to improve the rapid and intelligent identification of illegal parcels together with the sample database. Besides, given the current unclear boundaries of nature reserves and functional areas, the boundaries should be delimitated as soon as possible.

\section{ACKNOWLEDGEMENTS}

This research is supported by National Key R\&D Program of China (No. 2016YFE0205300) and Fundamental Research Fund for the Central Public-interest Scientific Institution (No. AR2001).

\section{REFERENCES}

Edwin, K., Adiel, M., Cyprian, N., 2019. Spatial-temporal changes in land use land cover and its impacts on wildlife conservation in meru conservation area, kenya. Asian Journal of Environment \& Ecology, 1-10.

Figure 7. Parcel 09 in Danjiang Wetland Nature Reserve

Feddema, J.J., Oleson, K.W., Bonan, G.B., Mearns, L.O., Buja, L.E., Meehl, G.A., Washington, W.M., 2005. The importance of land-cover change in simulating future climates. Science, 310(5754), 1674-1678.

Keenan, R.J., Reams, G.A., Achard, F., de Freitas, J.V., Grainger, A., Lindquist, E., 2015. Dynamics of global forest area: Results from the fao global forest resources assessment 2015. Forest Ecology and Management, 352, 9-20.

Laurance, W.F., Sayer, J., Cassman, K.G., 2014. Agricultural expansion and its impacts on tropical nature. Trends in Ecology \& Evolution, 29(2), 107-116.

Le Saout, S., Hoffmann, M., Shi, Y., Hughes, A., Bernard, C., Brooks, T.M., Bertzky, B., Butchart, S.H., Stuart, S.N., Badman, T., 2013. Protected areas and effective biodiversity conservation. Science, 342(6160), 803-805.

Liu, X., Hu, G., Chen, Y., Xia, L., Xu, X., Li, S., Pei, F., Wang, S., 2018. High-resolution multi-temporal mapping of global urban land using landsat images based on the google earth engine platform. Remote Sensing of Environment, 209, 227-239.

López-Angarita, J., Tilley, A., Hawkins, J.P., Pedraza, C., Roberts, C.M., 2018. Land use patterns and influences of protected areas on mangroves of the eastern tropical pacific. Biological Conservation, 227, 82-91.

MacDicken, K.G., 2015. Global forest resources assessment 2015: What, why and how? Forest Ecology and Management, $352,3-8$.

Mayra Cristina Prado, d.M., Kaline, d.M., Toppa, R.H., 2017. Protected areas and agricultural expansion: Biodiversity conservation versus economic growth in the southeast of brazil. Journal of Environmental Management, 188, 73-84.

Ministry of Natural Resources of the People's Republic of China, 2019. Content and index of fundamental geographic conditions monitoring, China.

Qian, D., Cao, G., Du, Y., Li, Q., Guo, X., 2019. Impacts of climate change and human factors on land cover change in inland mountain protected areas: A case study of the qilian mountain national nature reserve in china. Environmental Monitoring and Assessment, 191(8), 486. 
Rodríguez-Rodríguez, D., Martínez-Vega, J., Tempesta, M., Otero-Villanueva, M., 2015. Limited uptake of protected area evaluation systems among managers and decision-makers in spain and the mediterranean sea. Environmental Conservation, 42(3), 237-245.

Yu, H., Zhang, F., Johnson, V.C., Bane, C.S., Wang, J., Ren, Y., Zhang, Y., 2017. Analysis of land cover and landscape change patterns in ebinur lake wetland national nature reserve, china from 1972 to 2013. Wetlands Ecology and Management, 25(5), 619-637. 